\title{
DISCUSSION
}

\section{Group effects in stone column foundations: model tests}

\author{
D. MUIR-WOOD, W. HU and D. F. T. NASH (2000). Géotechnique 50, No. 6, 689-698
}

D. A. Greenwood, Geotechnical Consulting Group, formerly Cementation Piling \& Foundations

The model tests and theoretical treatment of stone column groups by Muir-Wood et al. confirm the hypothesis outstanding since the 1975 Conference that loading conditions strongly influence the stiffness and strength of stone columns (Greenwood, 1976). Except for colums near the edge of a loaded area that are not uniformly constrained nor wholly vertically loaded, the columns become stiffer and stronger as load is applied. In fact the applied load is the dominant influence on the strength and stiffness of columns. In the case of bulk storage tanks it is the live load that dominates the radial constraint on columns.

As a result, columns in large arrays under wide loaded areas such as embankments, ore stockpiles or oil tanks perform much better that those under narrow strips and pad footings where all columns are close to the edges of the footing and are thus constrained only by unloaded ground.

This fact demonstrates the futility of field load testing a small group of columns in the hope of representing their performance under wide loaded areas. Such tests will always show them to be less stiff and failing under lesser loads than those under large loaded areas. There is generally no practical and economic way of simulating stone column performance under wide loads.

For a comparable test the ambient stresses and excess pore water pressures generated by load must be accurately replicated. In my opinion this is more important for column behaviour at typical area ratios than mutual support from surrounding columns as suggested in the paper.

Money allocated for proving stone columns under wide loaded areas is best spent by supervising construction very closely to ensure that design specifications are consistently met (Greenwood, 1991).

\section{REFERENCES}

Greenwood, D. A. (1976). In Ground treatment by deep compaction, Institution of Civil Engineers, London, discussion pp. 107-109.

Greenwood, D. A. (1991). Load tests on stone columns. In Deep foundation improvements: design, construction and testing, ASTM STP 1089, pp. 148-171. Philadelphia: American Society for Testing and Materials. 